\title{
A articulação da experiência dos usuários nas microculturas dos Centros de Atenção Psicossocial - uma proposta metodológica ${ }^{1}$
}

\section{The articulation of users' experience in the microcultures of psychosocial health centers - a methodological proposal}

\section{Mônica de Oliveira Nunes*}

Professora do Instituto de Saúde Coletiva da Universidade Federal da Bahia - UFBA, Salvador, BA, Brasil

\section{Vládia J amile J ucá**}

Professora do Departamento de Psicologia da Universidade Federal do Ceará UFCE, Fortaleza, CE, Brasil

\section{Ana Maria Fernandes Pitta***}

Professora do Departamento de Neurociências e Saúde Mental da Universidade Federal da Bahia - UFBA, Salvador, BA, Brasil

\section{Maurice de Torrenté****}

Pesquisador Associado do Instituto de Saúde Coletiva da Universidade Federal da Bahia - UFBA, Salvador, BA, Brasil

\begin{abstract}
RESUMO
O objetivo primordial do presente artigo é apresentar uma metodologia de avaliação de centros de atenção psicossocial, enfocando seu componente qualitativo e multidimensional, e etapas de progressivo aprofundamento, a partir das perspectivas de usuários, familiares e profissionais. A proposta metodológica apresentada e discutida a seguir foi desenvolvida a partir da pesquisa intitulada "Articulando experiências, produzindo sujeitos e incluindo cidadãos: um estudo sobre as novas formas de cuidado em saúde mental na Bahia e em Sergipe, Brasil", realizada entre os anos de 2006 e 2009. Na construção do desenho metodológico desse estudo, percebemos que, para avaliar a qualidade de um serviço, é necessário congregar conceitos e técnicas diversos que nos permitam uma abordagem que responda à complexidade da tarefa de nos aproximar da experiência (através de suas expressões e produções de significados) dos atores sociais envolvidos, bem como identifique recursos psicossociais presentes nos CAPS e utilizados pelos usuários para significar sua experiência de sofrimento, articulada por "pontos de virada".
\end{abstract}

Palavras-Chave: Avaliação qualitativa, Centros de atenção psicossocial, Experiência da doença mental, Subjetividade, Idioma cultural. 


\begin{abstract}
This article's main objective is to present and discuss a methodology for the evaluation of psychosocial health centers, focused on qualitative and multidimensional elements, and steps towards a progressively deeper understanding, from the perspectives of users, family members and professionals. The present methodological proposal was developed for the research "Articulating experiences, producing subjects and including citizens: a study on the new forms of mental health care in Bahia and Sergipe, Brazil", realized between 2006 and 2009. While constructing the methodological design, we sensed that, in order to evaluate the quality of a service, it would be necessary to congregate various concepts and techniques to allow us to address the complexity of the task of approaching the involved social agents' experience (through its expressions and sense productions), as well as identify psychosocial resources available in the CAPS and employed by users to signify their experience of suffering, articulated around "turning points".
\end{abstract}

Keywords: Qualitative evaluation, Psychosocial health centers, Mental illness experience, Subjectivity, Cultural idiom.

\title{
I ntrodução
}

No campo da saúde mental, os problemas metodológicos para avaliar qualidade de serviços e tratamentos se multiplicam na medida em que formular critérios e standards de referência de boa e má prática não tem se constituído em rotina. A rigor, os sistemas de ajuizamento de valores têm sido estabelecidos de três modos. O primeiro se fundamenta nos estudos de "eficácia de tratamentos", pautados em "standards técnicos" definidos através da experiência de consenso entre os técnicos (FURTADO; CAMPOS 2008). Um segundo grupo de investigações, denominadas estudos de utilização de serviços, inclui desenhos de investigação que comparam características de estrutura do sistema de serviços de saúde, onde o processo de atenção é agora a variável principal e caberá identificar fatores de acessibilidade física, econômica e cultural que influenciam a utilização ou não de tais serviços pela população (ALMEIDA, 2003). Nesse grupo se destacam os estudos de efetividade, ou seja, como a oferta de serviços atinge a necessidade sentida pelos usuários (BARRIO ; CORIN; POREL; DROLET, 2004). A terceira linha de investigação explora os chamados estudos da eficiência da atenção, que avaliam o custo das intervenções.

A questão da avaliação da qualidade em Saúde Mental parece obedecer a características peculiares, quando comparadas às das demais áreas da saúde (FURTADO; ONOCKO, 2008). Ou seja, a mera extensão de cobertura, os quantitativos de números de consultas, internações, procedimentos laboratoriais, por si só, não parecem satisfazer critérios de boa qualidade em Saúde Mental. Todos os 
aspectos objetivos e materiais, mais que em outras áreas, estão atravessados pela intersubjetividade das relações entre usuários, trabalhadores e instituições de saúde (NUNES; TORRENTÉ; OTTONI; MORAES; SANTANA, 2008), aumentando as dificuldades já presumíveis nos processos de avaliação em serviços de saúde.

Saraceno; Frattura e Bertolote (1993) têm destacado a importância dos "indicadores soft" como contribuição àquilo que os estudos epidemiológicos trouxeram à luz nos últimos anos, valorizando variáveis negligenciadas anteriormente. Trata-se de "recursos invisíveis", "coloração afetiva-ambiental", "estilo de trabalho", que, associados aos "níveis de motivação" e às "expectativas" da equipe de "trabalho", constituem elementos decisivos na potencialização dos resultados existentes nos serviços. Analogamente, algumas características dos procedimentos de acolhida (cortesia, afabilidade, discrição, solidariedade, atenção aos acompanhantes) e tratamentos (presteza, eficácia, eficiência) estarão determinando a qualidade do cuidado, que, embora de difícil mensuração, se constitui no desafio dessas investigações (PITTA, A.; SILVA FILHO J.F.; SOUZA, G.W.; LANCMAN, S., KINOSHITA,R.T.; CAVALCANTI, M.T.; et al. , 1995).

Conceitualmente, avaliar pressupõe julgar, mensurar, emitir juízos de valor, objetivar mudanças estabelecendo um antes e um depois. Tradicionalmente, tem-se atribuído a capacidade de avaliar uma realidade à possibilidade de torná-la objetivada e, em geral, a objetivação numérica ou mensurável vem sendo aquela à qual mais se recorre. No entanto, é preciso notar que há dimensões da existência humana que são refratárias a processos de quantificação, entre elas e, especialmente, a subjetividade (UCHIMURA; BOSI, 2004). Não obstante, essas dimensões ou qualidades são imprescindíveis na tradução dos julgamentos que as pessoas fazem da sua própria realidade e dos efeitos sobre si e sobre os outros, bem como nas escolhas de situações e soluções para problemas (DAMÁSIO, 1995).

No campo da saúde mental, em que apreensões de mudanças de estado psíquico, interpretações de bem estar, de melhora e de felicidade se definem na esfera da subjetividade, essa dimensão se faz ainda mais relevante para avaliar a qualidade de práticas, ações ou tecnologias. Assim, conceitos como afeto, sentimento e emoção tornam-se carro-chefe na expressão de estados psíquicos ou psicossociais. Solomon (1976), um dos primeiros autores a operacionalizar o conceito de emoção, propõe concebê-lo enquanto "um sistema complexo de julgamentos sobre o mundo, sobre outras pessoas, e sobre si mesmo e nosso lugar no mundo" 2 (p. 187). Para Solomon, julgar o mundo e torná-lo significativo são aspectos primordiais conduzidos a partir da experiência emocional, ligando as emoções à intencionalidade e às inclinações para a ação. 
Essas reflexões, tendo impacto na criação da área da Antropologia das Emoções, serviram para estabelecer um novo estatuto para categorias, antes marginalizadas e relegadas ao plano de categorias confundidoras, imprecisas, inexatas, imponderáveis, inverificáveis, porque subjetivas, logo da ordem do não científico. No plano epistemológico à base das ciências humanas, assume-se então, cada vez mais, a impossibilidade de uma ciência fundada sobre a separação entre a subjetividade do pesquisador e a objetividade da realidade social: "o etnólogo não é um ser objetivo observando objetos, mas um sujeito observando outros sujeitos" (GHASARIAN, 2004, p. 10) ${ }^{3}$.

Para acessar de que modo as pessoas se posicionam frente às suas práticas, parte-se do pressuposto de que atribuir valor às ações humanas e avaliar o seu benefício ou malefício é um processo que ocorre cotidianamente. Geertz (1983, p. 77) propõe que o senso comum não se resume a uma "mera apreensão da realidade feita casualmente", mas diz respeito a uma "sabedoria coloquial, com pés no chão, que julga e avalia essa realidade", propondo estudá-lo dentro de uma perspectiva de sistema cultural. Nesse sentido, ele é "construído historicamente e sujeito, portanto, a padrões de juízo historicamente definidos".

A intenção da ciência seria de organizar, sistematizar e submeter a parâmetros de confiabilidade e validade aquilo que é produzido no senso comum. O risco se coloca na oposição entre esses dois saberes já que nem o senso comum é uma apreensão fixista, conservadora, naturalizada e mistificada da realidade, nem o conhecimento científico é totalmente desprovido de preconceitos, interesses e conservadorismo (SANTOS, 1989). O diálogo entre ciência e senso comum produziria o que esse autor chamou de "dupla ruptura epistemológica", com a possibilidade de benefício recíproco, no sentido de transformação da primeira em uma ciência prudente (enriquecida pela aproximação entre verdade científica e verdade social e pela sua submissão ao teste público da crítica) e do segundo em um senso comum esclarecido (iluminado pela perspectiva crítica da ciência, que tende a desconstruir verdades naturalizadas). Esta nova configuração se aproximaria da phronesis aristotélica, garantindo ao desenvolvimento tecnológico a sua transformação em um saber prático, ultrapassando, por sua vez, uma tendência contemplativa da ciência.

Reportando essas reflexões para o campo da pesquisa avaliativa, cuja finalidade é a "busca [de] subsídios para a solução de problemas práticos [...] e para a tomada de decisões" (FURTADO, 2006, p. 718), a ponderação acerca do necessário tensionamento entre objetividade e subjetividade, e, ainda mais, entre o ponto de vista do nativo e o ponto de vista do pesquisador (GEERTZ, 1997, p. 77), reorienta a compreensão de que a co-participação (ou co-autoria) na produção 
do texto avaliativo deve ser levado a sério, e não ser mero efeito de retórica. Por sua vez, o conhecimento produzido no percurso da ciência faculta abrir as reflexões já existentes no senso comum a novas descobertas, questionamentos, dúvidas ou corroborações, o que fortalece a idéia de uma avaliação formativa, e não meramente investigativa.

Essa aproximação entre universos de conhecimento exige uma postura dialógica e que supere posturas etnocêntricas. Ao mesmo tempo, levar em conta a opinião daqueles que produzem ou desfrutam do cuidado é sobremaneira incluir as suas experiências subjetivas das mesmas e suas vidas cotidianas (GONSETH, 1993). Perseguir esse objetivo, por sua vez, é um trabalho que transparece nas escolhas conceituais e metodológicas de cada pesquisa.

Entre os anos de 2006 e 2009, realizamos nos estados de Bahia e Sergipe um estudo intitulado "Articulando experiências, produzindo sujeitos e incluindo cidadãos: um estudo sobre as novas formas de cuidado em saúde mental na Bahia e em Sergipe, Brasil" que se concentrou na análise de Centros de Atenção Psicossocial. Esse estudo se inscrevia no domínio das pesquisas avaliativas, apresentando um desenho híbrido que incluía abordagens quantitativas e qualitativas. Embora híbrido, grande parte do nosso esforço foi concentrado no delineamento do componente qualitativo da pesquisa já que partíamos da premissa de que um dos nós críticos a ser superado, ao se partir para métodos menos estruturados de pesquisa, situava-se no enfrentamento da questão: qual desenho metodológico qualitativo pode dar conta do empreendimento avaliativo? Fundamentalmente, a questão que nos colocávamos era como produzir informações relevantes para uma pesquisa que quer tecer considerações avaliativas? Por sua vez se avaliações incluem subjetividade, emoção e experiência, como, então, aproximar-se dessas dimensões da existência do outro?

Esse artigo é uma tentativa de responder a esse desafio. Para tanto, faremos um recorte da metodologia proposta de modo a enfatizar o percurso definido para melhor acessar os agentes das práticas do cuidado em saúde mental, especialmente os próprios usuários, combinando - ou confrontando - suas vozes e destacando os contextos nos quais eles se inscrevem. Este recorte foi atribuído a partir da preocupação de alcançar dimensões mais profundas da realidade de atenção à saúde mental que produzam parâmetros avaliativos provenientes dos significados atribuídos às práticas.

\section{A articulação da experiência na abordagem antropológica}

$\mathrm{Na}$ antropologia, há algumas décadas, vem-se desenvolvendo um profícuo trabalho na direção de compreender a alteridade inscrita na experiência daqueles a quem se estuda. Este esforço se reflete cada vez mais no trabalho de campo, reflexões epistemológicas e 
monografias. Um desses reflexos, a virada interpretativista na antropologia, fortemente atravessada por abordagens teóricas como a hermenêutica e a fenomenologia, tomou as narrativas e as experiências dos sujeitos como objetos fundamentais de análise.

O uso da expressão "articulação de uma experiência" inscreve-se na perspectiva da abordagem fenomenológica. Parte-se da idéia de que experiências são fenômenos inapreensíveis na sua totalidade por serem vividos pelos sujeitos como um fluxo contínuo e, para apreendê-los, é necessário que sejam de algum modo "interrompidos", "registrados", "articulados" sobre a forma de uma experiência. Uma vez articulada, a experiência tomaria a forma de uma expressão e seria passível de acesso (BRUNER, 1986). As experiências são vividas sob a forma e articuladas a partir de linguagens que podem ser tomadas desde a perspectiva mais ampla de linguagens culturais, partindo do pressuposto de que culturas não são totalidades homogêneas, e podem se manifestar sob a forma de expressões tão diversas quanto narrativas, cantos, danças, rituais, pinturas, etc. Nesse sentido, apreender a experiência do outro significa mergulhar nas suas expressões as mais recônditas, compartilhá-las, estranhá-las, eventualmente, incorporá-las e, a partir desses movimentos espiralados, buscar compreendê-las.

O que estaria em jogo nessa articulação não seria a experiência, tomada na sua dimensão incomensurável de uma vivência abstrata e incessante, mas a sua comunicação por um esforço necessário de tradução para o outro e, simultaneamente, para si mesmo e, consequentemente, a sua continência em um espaço de concretude. Ao mesmo tempo, as articulações das experiências se inscrevem em construções sociais e históricas que lhes permitem a produção de significações particulares. Para a antropologia, o foco de interesse está na matriz cultural utilizada por uma pessoa para articular a sua experiência e nos recursos oferecidos por essa matriz para que uma experiência singular seja articulada.

Assim, no campo da saúde mental, podemos pensar nas formas singulares pelas quais pessoas psicóticas se situam face aos seus sintomas e recorrem, na tentativa de enfrentar dificuldades produzidas por suas aflições, a elementos de seu contexto cultural e social compondo um tipo de "bricolagem" com os mesmos (CORIN; LAUZON, 1992; NUNES, 1999). Essa perspectiva toma os recursos culturais a partir do agenciamento dos seus próprios atores sociais. Desse modo, existiriam culturas mais favoráveis do que outras ao manejo da experiência da loucura, por exemplo. Algumas sendo excessivamente normalizadoras e, consequentemente, mais intolerantes face à diferença e outras mais abertas e continentes. $\mathrm{Na}$ pesquisa que apresentamos nesse artigo, partimos do pressuposto de que os CAPS configuram microculturas produtoras de práticas sociais e que vão ser utilizadas pelos usuários como recurso para a 
articulação da sua experiência de vida. Idealmente essas microculturas deveriam produzir práticas desinstitucionalizadoras, contribuindo no processo de autonomia, desestigmatização e inclusão social de pessoas portadoras de transtornos mentais.

\section{Os Centros de Atenção Psicossocial como microculturas}

No nosso estudo, os diversos CAPS são tomados enquanto universos culturais próprios, com seus idiomas, práticas e significantes terapêuticos. Um idioma cultural refere-se a um conjunto de recursos, mecanismos e significantes que a cultura dispõe/cria de modo a permitir a articulação das experiências individuais e coletivas, produzindo-lhes sentido e ação concreta (CRAPANZANO, 1977). O que compõe a particularidade de um CAPS seria, portanto, a combinação de uma orientação idealmente pautada no modo psicossocial de cuidado com as peculiaridades aportadas pelos seus atores sociais e pelo contexto no qual se inscreve. Assim, em princípio, um CAPS deve distinguir-se de um hospital ou mesmo de um ambulatório psiquiátrico; nesse sentido haveria algo de comum em todos os CAPS. Ao mesmo tempo, os CAPS são diferentes entre si nas ênfases que colocam sobre determinadas ações (a geração de renda em detrimento da clínica, por exemplo), no grau de coesão da sua equipe, na ideologia de grupo que predomina ou orientação terapêutica, ou mesmo na dinâmica de grupo que prevalece entre os usuários. CAPS de cidades do interior tendem a seguir ritmos temporais diferentes de CAPS de capitais, como também desenvolvem relações sociais que tendem a gozar de uma maior familiaridade tendo em vista que o acesso à vida familiar dos usuários parece ser maior.

A singularidade dos universos culturais pressupõe ainda o papel da circulação dos saberes e das práticas provenientes das tradições culturais dos seus vários agentes. No campo da saúde, essas são fruto de vários modelos explanatórios, tidos por Kleinman (1978) como um conjunto de opiniões que contêm informações sobre um ou mais dos seguintes assuntos: etiologia, início dos sintomas, fisiopatologia, transcurso da doença (incluindo severidade e papel do doente), e tratamento. Na saúde mental incluem também saberes e práticas em vias de compartilhamento, fruto da difusão de princípios e diretrizes da Reforma Psiquiátrica, dos movimentos sociais, especialmente o movimento da luta antimanicomial, além das trajetórias pessoais tanto dos profissionais quanto dos usuários, privilegiando conceitos como lugar social, atuação política, empoderamento, exercício de cidadania, dentre outros.

Nesse sentido, o estudo de serviços de saúde e de suas tecnologias deve atentar para a diversidade dessas culturas institucionais, inclusive para "as culturas que se desenvolvem em espaços institucionais já marcados por estilos de gestão e práticas 
profissionais que repousam sobre uma história, que têm uma lógica própria e que podem pôr obstáculos às mudanças que se buscam introduzir" (CORIN ; BIBEAU; MARTIN; LAPLANTE, 1990, p.221) ${ }^{4}$.

Os CAPS são ainda sistemas abertos e de elevada complexidade. Desse modo eles se encontram em permanente intercâmbio com o seu meio (contexto/território), mas também são forjados na interação intensa entre os atores sociais que os atravessam. Estudálos demanda um olhar na direção de fora, ou seja, sobre as teias tecidas no espaço extramuros, e um olhar para dentro, quer dizer, para as tessituras relacionais que se desenvolvem no intramuros. Um estudo etnográfico de um CAPS requereria essa dupla empreitada, nem sempre fácil de ser empreendida. Normalmente, os pesquisadores acabam por realizar uma etnografia institucional que não explora o espaço e o tecido social que transbordam os limites físicos da instituição os quais, no entanto, ela propõe atingir. No caso da nossa pesquisa, combinamos estratégias metodológicas incluindo abordagens extensivas, que privilegiaram a comparação inter CAPS, e abordagens intensivas, que buscaram um mergulho em maior profundidade no intra CAPS, restrito a um número pequeno de serviços, como veremos no próximo subitem.

A diversidade e complexidade que caracterizam os CAPS justificam, além da comparação dos serviços entre si, respeitando as dimensões que Ihes permitem ser comparável, também a comparação do serviço tendo como base aquilo que, no momento, se considera como a melhor intervenção possível. Avaliar seria, portanto, confrontar o que vem sendo feito quotidianamente com o que deveria ser feito (SARACENO; FRATUURA; BERTOLLE, 1993) e isso pode ser estudado tanto a partir de uma perspectiva de ideal objetivo quanto de experiências concretas.

$\mathrm{Na}$ nossa pesquisa, essa comparação se fez a partir de etapas que incluíram progressivamente níveis mais profundos e complexos da realidade, como iremos detalhar a seguir. Nesse artigo, esse detalhamento servirá apenas como contexto que permitirá entender o processo até chegarmos à abordagem das histórias narrativas das pessoas que nos permitiu analisar a articulação das suas experiências a partir dos idiomas culturais dos CAPS.

\section{Estratégia metodológica da pesquisa}

Nesse estudo lançamos mão de uma combinação teóricometodológica com vistas a traçar um panorama da situação mais geral do funcionamento dos serviços, a partir do desenvolvimento de uma técnica de abordagem em extensão, quantitativa, sem perder em termos de compreensão desse funcionamento, o que se faz a partir de uma abordagem intensiva, ou em profundidade.

No componente quantitativo do estudo, foram utilizados dois instrumentos. O AVALIARCAPS que foi aplicado ao universo de CAPS 
da Bahia e de Sergipe, sendo respondido pelo gerente de cada CAPS. Esse instrumento foi enviado por e-mail ou por correio, após estabelecidos contatos telefônicos com cada município. O segundo instrumento foi o HUMANIZACAPS, aplicado a gerentes, profissionais, usuários e familiares referentes a 11 CAPS (04 situados em Aracaju e 07 situados na Bahia). Esses questionários foram aplicados por duplas de pesquisadores que se deslocaram para os vários municípios passando um total de três semanas em campo. A escolha das pessoas pesquisadas foi feita de modo aleatório por sorteio a partir dos prontuários de usuários em tratamento, por sorteio dos familiares, perfazendo um total de 30 questionários aplicados a usuários e familiares em cada CAPS, e cobriram o universo de trabalhadores de saúde mental, incluindo o gerente, presentes nas semanas em que estivemos em campo.

Para a consecução da abordagem qualitativa, realizamos o trabalho de produção de dados a partir de duas etapas: a etapa semi-intensiva e a etapa intensiva. Para essa abordagem, a escolha de um número grande de CAPS deveu-se ao fato de buscarmos uma perspectiva comparativa em vários planos. No plano interestadual, referente aos estados de Bahia e Sergipe, nos restringimos às respectivas capitais. No que tange à realidade baiana, queríamos ter uma perspectiva regionalizada e, por isso, escolhemos CAPS situados em macrorregiões distintas do estado. Finalmente, o terceiro componente comparativo dizia respeito às diferentes modalidades de CAPS (CAPS I, CAPS II, CAPS III, CAPSia e CAPSad), na intenção de identificar particularidades que diziam respeito ao tipo de clientela atendida, no que tange à faixa etária e aos tipos de transtornos mentais privilegiados, além do regime de funcionamento, se diurno, ou diurno e noturno.

$\mathrm{Na}$ etapa semi-intensiva, visitamos todos 11 CAPS, situados em 06 municípios (originalmente, eram 07, mas em um desses municípios o nosso estudo foi dificultado depois que houve mudança na coordenação de saúde mental do mesmo), por um período de 03 semanas. Para isso, dividimos os nossos pesquisadores em subequipes, cada uma responsável por um município em particular. Nesse período, realizamos observação sistemática do cotidiano desses CAPS, entrevistamos os gestores do município (secretário de saúde e coordenador de saúde mental) e os gerentes dos CAPS, realizamos grupos focais com os profissionais das equipes interdisciplinares que atuavam em cada CAPS, grupos focais com familiares (tentando, na medida do possível, convidar familiares assíduos e não assíduos nesses serviços) e, sempre que possível, realizamos entrevistas individuais com alguns usuários que se voluntariavam.

Para fins da observação sistemática, pedíamos para acompanhar o máximo possível de atividades desenvolvidas no que estamos 
chamando de uma "semana típica" de trabalho. Evidentemente que, fruto do imprevisto, acontecia que, em um ou outro CAPS, chegamos em algum momento especial, onde, por exemplo, na primeira semana, estava sendo realizada uma olimpíada ou um fórum de usuários. Nesse sentido, não somente essa semana era bem vinda para observar momentos extraordinários, como tínhamos a possibilidade de, nas outras duas semanas (que se faziam em geral, um mês depois da primeira), retornar ao nosso objetivo inicial de observar o mais ordinário.

$\mathrm{Na}$ etapa intensiva do estudo, escolhemos apenas três dentre os onze CAPS para uma abordagem etnográfica dos mesmos: dois CAPS II e um CAPSad. Todos esses CAPS foram escolhidos a partir de sua localização em Salvador, ou nas suas imediações. Essa escolha permitiria uma imersão maior no campo, como o demanda uma etnografia, tendo em vista que não dispúnhamos de membros na equipe disponíveis para passar um tempo longo fora de Salvador. Três subequipes permaneceram por, pelo menos, seis meses, em uma presença mínima de três vezes semanais nos serviços escolhidos, ou no seu território adscrito. Nessa etapa do estudo, definimos ainda que desenvolveríamos uma metodologia centrada no usuário. Ou seja, ele seria o ponto de partida para investigarmos o espaço e os atores sociais com ele envolvidos. Centramos a nossa metodologia sobre a observação participante que permitia a produção de relatos em diário de campo. Nesse período, não apenas o cotidiano do CAPS permanecia sob a nossa mira, mas começamos a explorar o território ao seu redor.

A metodologia centrada no usuário nos conduziu a algumas tomadas de decisão. A primeira delas foi a utilização de técnicas voltadas para uma construção aprofundada da história de certos usuários de cada um desses CAPS. Realizamos uma entrevista narrativa em profundidade com cada um deles (o que podia significar mais de uma entrevista com cada um). Em seguida, a partir da análise das entrevistas narrativas, destacamos situações ou experiências na vida desses usuários que se revelassem para os mesmos como aspectos suficientemente significativos para serem entendidos como "pontos de virada" nas suas vidas. Esses "pontos de virada" poderiam ser, por exemplo, a própria eclosão da enfermidade, a perda de alguém importante, mas poderiam também ser representados pela experiência de ser cuidado no CAPS, ou pela conquista de um lugar de trabalho, uma relação amorosa, dentre outros. A identificação desses pontos de virada nos conduzia a explorá-los em maior profundidade a partir da adaptação de um instrumento com esse nome em inglês "Turning Point", desenvolvido, na Universidade McGill, pela Professora Ellen Corin e seus colaboradores. Entrevistas baseadas nesse instrumento eram aplicadas então não apenas ao próprio usuário em questão, mas 
também a um familiar e um profissional, escolhidos pelo usuário como sendo pessoas que tivessem bastante proximidade com 0 mesmo. O objetivo dessas entrevistas era de verificar em que medida haveria pontos de confluência ou de dissonância entre os aspectos significativos e a rede semântica e interpretativa, produzidos a partir da experiência do próprio usuário e daqueles que lhe são próximos.

Outro aspecto relevante da etapa intensiva é que a aproximação do território por parte dos pesquisadores deveria seguir prioritariamente as travessias propostas pelos usuários. Assim, o principal território a ser explorado pelos pesquisadores deveria ser o território geográfico, social e afetivo-existencial vivido pelos usuários em questão. Os usuários escolhidos para serem estudados em profundidade foram em média três por serviço e essa escolha seguia alguns critérios relevantes: buscava-se ter homens e mulheres, todos deveriam ter pelo menos um ano de inserção no CAPS e deveriam diferir em termos de adesão às atividades do CAPS e de níveis de reinserção (ou inclusão) social. Outros critérios relevantes de inclusão eram o nível de proximidade obtido entre o usuário e o pesquisador que o acompanharia e a disposição do usuário manifestada para, e desenvoltura na, realização dessas entrevistas. Evidentemente que, para se chegar a esses usuários, o trabalho de campo começou de forma mais ampliada, tendo os pesquisadores conversado e observado muitos deles e muitas atividades no espaço intra e extramuros do CAPS, além de terem também conversado com muitos profissionais e familiares que transitavam pelo CAPS. Com isso, pôdese descrever com maior densidade o contexto cultural e social desses CAPS e, até certo ponto, de seus territórios afins.

No próximo item, descreveremos de que modo o recurso às histórias dos usuários contadas pelos mesmos, por seus familiares e por seus terapeutas permite lançar um olhar avaliativo sobre os CAPS que destaque aspectos institucionais que ganham relevância na articulação da vida dos sujeitos psicóticos, evidenciados na trama das narrativas desses três atores sociais.

\section{Parâmetros avaliativos: os CAPS e a articulação da experiência dos sujeitos}

Avaliar uma intervenção pressupõe definir claramente alguns parâmetros a partir dos quais estabelecemos um julgamento que delineia um antes de um depois. Embora quando falamos de cuidado em saúde mental, esses parâmetros possam ser numerosos, para fins desse artigo podemos resumi-lo ao deslocamento do lugar social de sujeitos acometidos por sofrimento psíquico intenso e ao modo como o cuidado no CAPS produz efeito na redução desse sofrimento. De modo mais explícito, poder-se-ia associar redução de sofrimento a novas formas de fazer andar a vida que resultem de uma mediação entre a forma particular de estar no mundo, provocada por uma 
experiência psicótica, e as exigências e pressões exercidas pela vida em sociedade, especialmente aquelas que produzem mais sofrimento e mal estar.

Nessa direção, trabalhamos com um eixo analítico da inclusão social dos sujeitos compreendido enquanto recursos (estratégias, práticas e significantes culturais) que o CAPS disponibilizaria ou buscaria articular no sentido de permitir aos usuários lidar com os seus sintomas enquanto dimensões de uma experiência humana produtora de sentidos e que desenvolva mecanismos que lhes favoreçam o "gerenciamento da vida" (GOLDBERG, 1994), o aumento do "poder de contratualidade" (TYKANORI, 2001) e a mudança de lugar no espaço social. Para este autor, o resgate do poder contratual envolve potencializar a capacidade desses sujeitos de participar dos intercâmbios sociais relativos à troca de afetos, de mensagens e de bens. Para atingir esse propósito, alguns recursos são utilizados, acentuando-se os de caráter grupal: as oficinas e grupos terapêuticos. Outras estratégias utilizadas são realizadas na modalidade extra-muros como as atividades de lazer e os projetos comunitários. Em linhas gerais, trata-se de um conjunto de recursos que visam trabalhar o sujeito e seus laços sociais, configurando o que se reconhece como "clínica ampliada" (BEZERRA JÚNIOR, 2001).

Esses recursos são ofertados a partir de linguagens distintas tais como expressão verbal, visual, musical, corporal, etc. Essa diversidade de linguagens oferecidas pelos CAPS favorece trânsitos e adesões a modos possíveis de traduzir o estranhamento de certas experiências, de dar forma a vivências caóticas e desprovidas de sentido, ou de definir esteticamente produções criativas, exuberantes e incomuns dentro do universo simbólico socialmente compartilhado. Essas linguagens são compostas por significantes que podem ser desde cores, imagens, músicas, gestos, movimentos, objetos e palavras. Elas dispõem também de mecanismos que, por exemplo, favorecem o estabelecimento de laços sociais ou permitem ao psicótico proteger-se de reações sentidas como invasivas.

Observa-se que a diferença de estratégias de manejo da pessoa psicótica tem implicações evidentes sobre a valoração de aspectos da sua experiência que servirão ao estabelecimento de critérios de melhora ou piora, logo a procedimentos avaliativos. Isso se aplica aos profissionais de saúde, à família e aos próprios psicóticos. Não raramente, essa escala de valores é progressivamente incorporada por esses últimos que passam a "moldar" comportamentos em função de expectativas sociais. Se essa é uma dinâmica inevitável, uma vez que se vive em sociedade, o que não é desejável, e, portanto, deveria ser submetido a crítica, seria o furor normalizador que reduz as experiências humanas a scripts restritos e pré-estabelecidos de comportamentos normais e patológicos. 
Como saber, no entanto, em que medida um CAPS se estrutura a partir de um idioma de orientação psicossocial e maneja esse conjunto de recursos, significantes e mecanismos? $\mathrm{Na}$ nossa pesquisa, recorremos à combinação de duas estratégias. De um lado, tanto na etapa semi-intensiva quanto na intensiva, confrontamos narrativas de usuários, familiares e profissionais a partir de temas semelhantes, que funcionaram como categorias analíticas, tais como processos de inclusão social (o que inclui acesso a trabalho formal e informal, rede de apoio social, estabelecimento de relações afetivas e amorosas), aspectos reconhecidos como melhora clínica, adesão ao tratamento, avaliação das práticas de cuidado e manejo das crises. De outro lado, unicamente nos CAPS onde ficamos em uma imersão mais profunda, buscamos identificar, a partir de histórias de vida, elementos da experiência de usuários articulados a partir do idioma cultural psicossocial além de evidenciar pontos de virada nas suas vidas atribuídos à experiência no CAPS, verificando em que medida eram significados de modo positivo ou negativo, de que forma eram considerados como recursos estruturantes, fatores de proteção, elementos de suporte. Analisávamos também até que ponto os significantes oferecidos por esse idioma eram utilizados na bricolagem de uma expressão idiossincrática, na tradução de um modo particular de estar no mundo que permitisse ao sujeito uma existência própria e autônoma.

Evidentemente que toda história de vida é o resultado de uma combinação complexa de vetores de determinação que fazem com que múltiplos fatores incidam sobre os resultados de uma experiência, dentre as quais uma melhora clínica, um sentimento de maior bem estar, uma mudança de lugar social, uma dinamização nas interações sociais, uma produção de laço social. Qualquer associação exclusivista corre o risco de reducionismo. No entanto, buscar julgamentos ou ajuizamentos de realidades, nesse caso experiências em CAPS, por intermédio do relato de narrativas não tem a pretensão de mensurar efeitos das ações desenvolvidas no serviço sobre a vida de uma pessoa, mas qualificá-los. Nessa perspectiva, interpretamos as narrativas com ferramentas que uma análise hermenêutica oferece, aspecto que não poderemos desenvolver nesse artigo.

\section{Considerações finais}

Acenar para a importância de incluir a dimensão subjetiva nas avaliações de serviços aponta para a perseguição de um novo tipo de rigor metodológico - aquele que busca apreender a complexidade das percepções e expectativas dos atores envolvidos nesses serviços. Percepções e expectativas, por sua vez, são nuançadas a partir de valores sociais e de experiências pessoais. Avaliar qualidades é, portanto, antes de tudo, compreender significados produzidos em contextos sociais específicos. Como propusemos anteriormente, as 
pessoas buscam comunicar-se com as outras pela produção de expressões que permitem traduzir experiências. Acessar as experiências implica em interpretar os significados dessas expressões, como aqueles que emergem da articulação das experiências dos sujeitos através de um dado idioma cultural.

Em nossa pesquisa, conversamos com pessoas que guardam consigo suas vivências, boas ou más, em centros de atenção psicossocial. Buscamos saber se essa vivência afeta (ou não) suas vidas e oferece recursos simbólicos e materiais para que estas sejam articuladas, ou seja, ganhem sentido. Estávamos interessados em destrinchar esses sentidos, verificar em que medida havia convergência entre interpretações realizadas por diferentes agentes, estabelecer os matizes das colorações afetivas tingidas por essa experiência, sentir a força dos vínculos e a tradução de todos esses elementos nos pontos de virada que alteraram trajetórias de vida, ou nas bricolagens de significantes que incidiram na redução do sofrimento. Queríamos compreender experiências a partir da passagem de pessoas pelos CAPS e suscitar comparações dessas com outras experiências próprias (por exemplo, experiências em hospitais, ou no ambiente familiar) e alheias (como familiares e profissionais vivenciam essas passagens).

Pode-se concluir dizendo que suscitar pessoas a falar densamente (em uma analogia à descrição densa proposta por GEERTZ, 1973, p. 78) dos efeitos que um tipo de serviço tem provocado sobre suas vidas faz do ato avaliativo também um ato de criação. Julga-se o mundo ao mesmo tempo em que o transforma, transformando-se a si mesmo a partir da descoberta, da constatação, da dúvida. Trata-se do efeito agissante da palavra. No entanto, sabe-se da insuficiência que esse primeiro ato da pesquisa provoca. Para que esta seja plena, um desafio importante é o de transformar os seus resultados em insumo político para as transformações necessárias dos serviços, o que, necessariamente, envolverá outros atores sociais.

\section{Referências Bibliográficas}

ALMEIDA, P. F. O desafio da produção de indicadores para avaliação de Serviços de Saúde Mental: um estudo de caso do Centro de Atenção Psicossocial Rubens Corrêa, RJ. In: AMARANTE, P. (Org.). Archivos de saúde mental e atenção psicossocial. Rio de Janeiro: Nau Editora, 2003, p. 121-148.

BARRIO, L. R. del; CORIN, E.; POREL, M. L.; DROLET, M. Avaliação qualitativa de serviços de saúde mental a partir das perspectivas de usuários e profissionais - negociação, cidadania e qualidade dos serviços. In: BOSI, M. L. M.; MERCADO, F. J. (Orgs.). Pesquisa qualitativa de serviços de saúde. 2. ed. Petrópolis: Vozes, 2004, p. 401-450. 
BEZERRA JUNIOR, B. A clínica e a reabilitação psicossocial. In: PITTA, A. (Org.). Reabilitação psicossocial no Brasil. 2. ed. São Paulo: Hucitec, 2001, p. 137-142.

BRUNER, E. M. Experiences and its expressions. In: TURNER, V.W; BRUNER, E. M. (Eds.). The Anthropology of experience. Urbana: University of Illinois Press, 1986, p.3-30.

CORIN, E.; BIBEAU, G.; MARTIN, J. C. ; LAPLANTE, R. Comprendre pour soigner autrement. Montreal: Les Presses de l'Université de Montréal; 1990.

CORIN, E.; LAUZON, G. Positive withdrawal and the quest for meaning: the reconstruction of experience among schizophrenics. Psychiatry, v. 55, n. 3, p. 266-278, 1992.

CRAPANZANO, V. Introduction. In : CRAPANZANO, V.; GARRISON, V. (Ed.). Case studies in spirit possession. New York: John Wiley, 1977, p. 1-39.

DAMÁSIO, A. O erro de Descartes. Lisboa: Círculo de Leitores e Europa-América, 1995.

FURTADO, J. P.; ONOCKO CAMPOS, R. A participação de diferentes grupos de interesse na geração de conhecimentos sobre a rede de serviços avaliada. In: ONOCKO CAMPOS, R.; FURTADO, J. P.; PASSOS, E.; BENEVIDES, R. (Orgs.). Pesquisa avaliativa em saúde mental. São Paulo: Hucitec, 2008, p. 231-248.

FURTADO, J. P. A avaliação de programas e serviços. In: CAMPOS, G. W. S.; MINAYO, M. C. (Orgs.). Tratado de saúde coletiva. São Paulo: Hucitec, 2006, p. 715-740.

GEERTZ, C. The interpretation of cultures. New York: Basic Books, 1973.

Common sense as a cultural system. In:

Local

knowledge. New York: Basic Books, 1983, p. 73-93.

. Do ponto de vista dos nativos: a natureza do entendimento antropológico. In: _. 0 saber local: novos ensaios em Antropologia interpretativa. Petrópolis: Editora Vozes, 1997, p. 85- 107.

GHASARIAN, C. Sur les chemins de l'ethnographie réflexive. In: GHASARIAN, C. (Dir.). De l'ethnographie à l'anthropologie réflexive. Paris: Armand Colin, 2004, p. 5-33.

GOLDBERG, J. Clínica da psicose: um projeto na rede pública. Rio de Janeiro: TeCorá/Instituto Franco Basaglia, 1994.

GONSETH, M. O. L'ordinaire et son ombre. In: HAINARD, J. ; HAEHR, R. (Orgs.). Si... Regards sur le sens commun. Neauchâtel: Musée d'Ethnographie, 1993, p. 22-50.

KLEI NMAN, A. Concepts and a model for the comparison of medical systems as cultural systems. Soc. Sci. and Med., v.12, p.85-93, 1978.

NUNES, M. O. À temps et à contre-temps: les voix des tambours dans l'expérience des psychotiques. Tese (doutorado em 
Antropologia), 1999, 387p., Département d'Anthropologie, Université de Montréal, Montreal.

NUNES M. O.; TORRENTÉ, M.; OTTONI, V.; MORAES, V.; SANTANA, M. A dinâmica do cuidado em saúde mental: signos, significados e práticas de profissionais em um Centro de Assistência Psicossocial em Salvador, Bahia, Brasil. Cad. Saúde Pública, v.24, n.1, p.188-196, 2008.

PITTA, A.; SILVA FILHO J. F.; SOUZA, G. W.; LANCMAN, S., KINOSHITA, R. T.; CAVALCANTI, M. T.; et al. Determinantes da qualidade de serviços de saúde mental em municípios brasileiros Estudo da satisfação com os resultados das atividades desenvolvidas por pacientes, familiares e trabalhadores de serviços. Jornal Brasileiro de Psiquiatria, v.44, n.9, p.441-452, 1995.

SANTOS, B. S. Ciência e senso comum. In: I ntrodução a uma ciência pós-moderna. Rio de J aneiro: Graal, 1989, p.31-46.

SARACENO B.; FRATTURA L.; BERTOLOTE, J. M. Evaluation of psychiatric services: hard and soft indicators in innovative approaches in service evaluation: consumer contribution to qualitative evaluation - soft indicators. Geneva: WHO/MNH/ MND/93.19, 1993.

SOLOMON, R. The passions. The myth and nature of human emotions, Oxford, England: Anchor, 1976.

TYKANORI, R. Contratualidade e reabilitação psicossocial. In: PITTA, A. (Org.). Reabilitação psicossocial no Brasil. 2. ed. São Paulo: Hucitec, 2001, p.55-59.

UCHIMURA K. Y.; BOSI, M. L. M. A polissemia da qualidade na avaliação de programas e serviços de saúde - Resgatando a subjetividade. In: BOSI, M. L. M.; MERCADO, F. J. (Orgs.). Pesquisa qualitativa de serviços de saúde. 2. ed. Petrópolis: Vozes, 2004, p.7598.

\author{
Endereço para correspondência \\ Mônica de Oliveira Nunes \\ Rua Basílio da Gama, s/n, Campus Universitário do Canela, CEP 40110-140, \\ Salvador - BA, Brasil \\ Endereço eletrônico: nunesm@ufba.br \\ Vládia Jamile Jucá \\ Av. da Universidade 2762, Benfica, CEP 60020-181, Fortaleza - CE, Brasil \\ Endereço eletrônico: vladiajuca@gmail.com \\ Ana Maria Fernandes Pitta \\ Hospital das Clínicas Geral, Rua Augusto Viana 1, CEP 40110-060, Salvador - BA, \\ Brasil \\ Endereço eletrônico: anapitta@ufba.br \\ Maurice de Torrenté \\ Rua Basílio da Gama, s/n, Campus Universitário do Canela, CEP 40110-140, \\ Salvador - BA, Brasil \\ Endereço eletrônico: maurice@ufba.br
}

Recebido em: 30/07/2009 
Aceito para publicação em: 04/11/2009

Acompanhamento do processo editorial: Deise Mancebo, Roberta Romagnoli e Marisa Lopes da Rocha

\section{Notas:}

* Ph.D. em Antropologia

** Doutorado em Saúde Coletiva

*** Doutorado em Medicina Preventiva e Saúde Mental

$* * * *$ M.Sc. em Antropologia

${ }^{1}$ Agradecimentos: Este estudo foi financiado através do Edital MCT-CNPq / MS-

SCTIE-DECIT / CT-Saúde 07/2005, pelo que agradecemos imensamente o apoio.

${ }^{2}$ Destaque e tradução nossos.

3 Tradução nossa.

${ }^{4}$ Tradução nossa. 